\title{
Aplikasi Website Pendaftaran Perpanjangan Sim Pada Mobil Sim Keliling Polres Sukabumi Kota
}

\author{
Dendi Firmansyah ${ }^{1}$, A. Gunawan ${ }^{2}$ \\ 1,2 Universitas Bina Sarana Informatika \\ 1dendiifirmansyah@gmail.com, ${ }^{2}$ a.gunawan.agn@bsi.ac.id
}

\begin{abstract}
Currently the service of making a Driving License (SIM) carried out by police officers is not in accordance with the wishes of the community. The attitude of the officers in providing services is less able to maintain work relations and less to create satisfaction to the people served, for example the efficiency of time in service, ease of service, and fairness of service. Related to this, the Indonesian National Police made efforts to improve services and improvements with the innovation related to the making and extension of SIMs, such as the Sukabumi City Police who implemented an online SIM Extension System on Mobile SIM Cars. The online SIM extension system will help make it easier for the public, especially those who want to increase the validity period of the SIM. Applicants will be directed directly to fill in their data in the form provided by attaching a Scan of KTP or Identity Card and old SIM. The registration system for web-based SIM extension on SIM Cars around Sukabumi Police is expected to facilitate SIM Applicants in extending SIM without having to queue for long at mobile SIM cars, but can be accessed anywhere. SIM applicants can easily print proof of registration in which there is already a queue number for taking a new SIM.
\end{abstract}

\section{Keywords: Application Program, Registration, SIM Extension}

\begin{abstract}
Abstrak: Saat ini pelayanan pembuatan Surat Izin Mengemudi (SIM) yang dilaksanakan oleh petugas kepolisian tidak sesuai dengan keinginan masyarakat. Sikap petugas dalam memberikan pelayanan kurang dapat memelihara hubungan kerja serta kurang menciptakan kepuasan kepada masyarakat yang dilayani, misalnya efesiensi waktu dalam pelayanan, kemudahan pelayanan, dan keadilan pelayanan. Terkait hal tersebut, Kepolisian Republik Indonesia melakukan upaya pelayanan dan pembenahan dengan adanya inovasi terkait pembuatan dan perpanjangan SIM, seperti yang dilakukan Polres Sukabumi Kota yang menerapkan Sistem Perpanjangan SIM online pada Mobil SIM Keliling. Sistem perpanjangan SIM online akan membantu memudahkan masyarakat khususnya Pemohon yang ingin menambah masa berlaku SIM. Pemohon akan diarahkan langsung untuk mengisi data diri di form yang sudah disediakan dengan melampirkan Scan KTP atau Kartu Identitas dan SIM lama, Sistem pendaftaran perpanjangan SIM berbasis web pada Mobil SIM keliling Polres Sukabumi diharapkan dapat mempermudah Pemohon SIM dalam melakukan perpanjangan SIM tanpa harus antri lama di mobil SIM keliling, melainkan bisa diakses dimana saja. Pemohon SIM dapt dengan mudah mencetak bukti pendaftaran yang didalamnya sudah terdapat nomor antrian untuk pengambilan SIM baru.
\end{abstract}

Kata kunci: Program Aplikasi, Pendaftaran, Perpanjangan SIM

\section{A. PENDAHULUAN}

Banyaknya kecelakaan lalu lintas jalan raya yang terjadi disebabkan oleh pengemudi itu sendiri yang kurang hati-hati dalam mengendarai kendaraan bermotor serta kurangnya pengetahuan akan rambu-rambu peraturan lalu lintas jalan raya. Pelanggaran lalu lintas sering 
terjadi dimana-mana baik di kota maupun di desa, salah satunya adalah pengemudi kendaraan bermotor (ranmor) yang tidak memiliki Surat Izin Mengemudi (Anggraini, 2019)].

Syarat mutlak bagi para pengendara kendaraan bermotor harus memiliki SIM atau Surat Ijin Mengemudi yang merupakan bukti registrasi dan identifikasi yang diberikan oleh Polri kepada seseorang yang telah memenuhi persyaratan administrasi, sehat jasmani dan rohani, memahami peraturan lalu lintas dan terampil mengemudikan kendaraan bermotor (Https://www.polri.go.id, 1992). Saat ini pelayanan pembuatan Surat Izin Mengemudi (SIM) yang dilaksanakan oleh petugas kepolisian tidak sesuai dengan keinginan masyarakat. Sikap petugas dalam memberikan pelayanan kurang dapat memelihara hubungan kerja serta menciptakan kepuasan kepada masyarakat yang dilayani, misalnya efesiensi waktu dalam pelayanan, kemudahan pelayanan, dan keadilan pelayanan (Suryani, Des, 2018).

Dalam pelayanan perpanjangan SIM sarana dan prasarana lebih utama tetapi sarananya sudah ada kemudian dengan prasarananya masih kurang, misalnya kurangnya penyediaan kursi karena jumlah $25 \mathrm{~s} / \mathrm{d} 30$ orang per harinya, tidak adanya tenda untuk berteduh, tidak adanya meja buat mengisi formulir, dan juga terkadang pada saat melayani masyarakat dalam perpanjangan SIM genset tiba-tiba rusak dan tidak ada cadangannya, apabila rusak terpaksa diberhentikan proses pelayanan perpanjangan dan menunggu sampai baik atau diperbaiki (Putra, 2016a). Terkait hal tersebut, Kepolisian Republik Indonesia melakukan upaya pelayanan dan pembenahan dengan adanya inovasi terkait pembuatan dan perpanjangan SIM (Rustopo, 2016), seperti yang dilakukan Polres Sukabumi Kota yang menerapkan Sistem Perpanjangan SIM online pada Mobil SIM Keliling.

Prosedur Perpanjangan SIM yang ada pada Satlantas Polres Sukabumi Kota saat ini masih menggunakan sistem manual, yaitu Pemohon datang ke tempat penerbit SIM, mengambil nomor antrian dan mengisi formulir pendaftaran. Setelah mengisi formulir, biaya perpanjangan dan asuransi kecelakaan diri pengemudi, kemudian pemohon akan difoto, tandatangan dan SIM akan diterbitkan oleh Polri. Hal tersebut dirasa kurang efisien dalam segi waktu dan prosesnya, maka perlu ada inovasi baru melalui penerapan teknologi komputer untuk mempermudah dalam pelayanan perpanjangan SIM.

Sistem perpanjangan SIM online akan membantu memudahkan masyarakat khususnya Pemohon yang ingin menambah masa berlaku SIM. Dengan membuka website, Pemohon akan diarahkan langsung untuk mengisi data diri di form yang sudah disediakan dengan melampirkan Scan KTP atau Kartu Identitas dan SIM lama. Setelah selesai, pemohon bisa mendownload bukti pendaftaran perpanjangan SIM yang sudah tertera nomor regtistrasi untuk melakukan foto, tandatangan dan pengambilan SIM yang baru di Mobil SIM keliling sesuai jadwal yang dipilih.

\section{B. TINJAUAN PUSTAKA}

1. Aplikasi

(Sutabri, 2012:147) menjelaskan bahwa "Aplikasi adalah alat terapan yang difungsikan secara khusus dan terpadu sesuai kemampuan yang dimilikinya", sementara (Asropudin, 2013:6) memaparkan "Aplikasi merupakan software yang dibuat oleh suatu perusahaan komputer untuk mengerjakan tugas-tugas tertentu". Pendapat lain dikemukakan oleh (Henry, 2014:12), yang menyatakan bahwa "Aplikasi adalah suatu unit perangkat lunak yang dibuat untuk melayani kebutuhan akan beberapa aktifitas seperti perniagaan, pelayanan masyarakat, periklanan atau semua proses yang dilakukan manusia".

Dari beberapa penjelasan diatas, maka dapat disimpulkan bahwa aplikasi adalah program siap pakai yang dapat digunakan untuk menjalankan perintah-perintah dari pengguna aplikasi tersebut dengan tujuan mendapatkan hasil yang lebih akurat sesuai dengan tujuan pembuatan aplikasi tersebut, aplikasi mempunyai arti yaitu pemecahan masalah yang menggunakan salah satu tehnik pemrosesan data aplikasi yang biasanya berpacu pada sebuah komputasi yang diinginkan atau diharapkan maupun pemrosesan data yang diharapkan.

\section{Teknologi Website}

a. Website

Website merupakan kumpulan halaman web yang saling terkait, berisi kumpulan informasi yang berasal dari individu maupun organisasi dengan menggunakan web browser untuk mengaksesnya di dalam jaringan internet atau intranet. 
b. HTML

HTML (Hyper Text Mark Up Language) merupakan bahasa yang digunakan untuk mendeskripsikan struktur sebuah halaman web. HTML berfungsi untuk mempublikasi dokumen online (Pahlevi, Mulyani, \& Khoir, 2018).

c. PHP

PHP merupakan script bahasa pemrograman server, dan merupakan tool yang kuat dalam membuat halaman Web yang dinamis dan interaktif. Saat ini PHP sudah merelease versi PHP 7.1.24.

Beberapa peningkatan PHP 7 (Abidin, 2016), antara lain:

1) Kinerja

Terdapat banyak fitur peningkatan kinerja PHP 7 salah satunya adalah peningkatan performa maksimal pada HHVM.

2) Scalar Type Hints \& Return Types

PHP 7 dapat menyatakan fungsi Return Types guna mengembalikan nilai.

3) Spaceship Operator

Memperkenalkan operator baru Spaceship Operator $(<=>)$ atau operator perbandingan gabungan yang digunakan dalam memilih dan mengkombinasikan perbandingan.

4) Fitur Tambahan

Beberapa fitur baru seperti Abstract Syntax Tree, Closure::call(), Null Coalesce Operator, Uniform Variable Syntax, dll.

d. MySQL Database

MySQL adalah Relational Database Management System (RDBMS) bersifat open source berdasarkan Structured Query Language (SQL) yang didukung oleh Oracle. MySQL berjalan di hampir semua platform, termasuk Linux, UNIX dan Windows. Meskipun dapat digunakan dalam berbagai aplikasi, MySQL paling sering dikaitkan dengan aplikasi web dan penerbitan online (Rouse, 2018).

e. Bootsrap

Bootstrap merupakan toolkit open source untuk dikembangkan bersama dengan HTML, CSS, dan JS. Bootstrap dapat dengan cepat dalam membuat prototype aplikasi dengan Sass variable dan mixins, sistem jaringan responsif, komponen prebuilt ekstensif, dan plugin kuat yang dibangun di jQuery (Bootstrap, 2018).

3. Pendaftaran Perpanjangan SIM

Surat ljin Mengemudi merupakan jenis ijin yang bersifat perorangan (persoonlijkevergnning), oleh karena itu Surat Izin Mengemudi penerbitannya memerlukan persyaratan tertentu yang dikaitkan dengan kondisi pemegang Surat Izin Mengemudi.(Suhartono, 2015)

Pendaftaran Perpanjangan SIM dapat diartikan sebagai proses pencatatan data diri menambah masa waktu berlaku SIM yang sudah habis dengan melampirkan SIM asli yang habis masa berlakunya dan salinan identitas diri atau KTP (Suryawan, 2015) Pendapat lain dikemukakan oleh (Kardianawati, 2014) yang menjelaskan bahwa perpanjangan SIM adalah perpanjangan masa berlaku Surat ljin Mengemudi dimana masa berlaku SIM tersebut telah habis dalam rentang waktu tertentu, dan rentang waktu masa berlaku SIM adalah 5 tahun. Adapun untuk prosedurnya yaitu: Pemohon datang ke Polda atau Polres penerbit SIM dan mengisi formulir pendaftaran, setelah mengisi formulir, biaya perpanjangan dan asuransi kecelakaan diri pengemudi, kemudian pemohon akan difoto, tandatangan dan SIM akan diterbitkan oleh Polri.

Sedangkan untuk pengertian SIM Keliling adalah fasilitas pelayanan bagi masyarakat dalam mengurus pendaftaran maupun perpanjangan SIM berdasarkan jadwal dan tempat yang sudah ditentukan. Pelayanan SIM Keliling dalam rangka meningkatkan pelayanan kepada masyarakat untuk memberikan pelayanan yang baik. Dengan adanya SIM keliling ini agar masyarakat tidak perlu datang ke Kantor Polisi, masyarakat cukup mendatangi mobil SIM Keliling yang beroperasi sesuai dengan jadwal yang sudah di tentukan sesuai dengan keperluan masyarakat dan masyarakat juga tidak perlu melaksanakan ujian SIM lagi dengan demikian masyarakat sangat terbantu (Putra, 2016b).

Prosedur demikian sangat sederhana, cepat, murah, dan mudah, sehingga sangat menguntungkan masyarakat, karena pemohon perpanjangan Surat Izin Mengemudi tidak perlu datang ke kantor penerbitan Surat Izin Mengemudi. Pelayanan demikian tentunya sangat 
efisien dari segi waktu, tenaga, dan biaya, karena pemohon perpanjangan dapat mendatangi mobil layanan perpanjangan Surat Izin Mengemudi yang paling dekat dengan rumah atau tempat kerjanya. Dari segi biaya juga lebih murah, dan dari waktu lebih efisien, karena cepat pelayanannya, sebab pemohon tidak perlu menjalani serangkaian test yang disyaratkan, dan juga lebih praktis, karena dapat dijangkau dari rumah atau tempat kerja sewaktu-waktu atau dalam waktu tertentu di sela-sela kesibukan (Suhartono, 2015).

\section{Mobil SIM Keliling}

Penelitian yang dilakukan oleh (Suhartono, 2015) mengenai Perpanjangan SIM Melalui Mobil Layanan dan SIM Corner. Perpanjangan Surat ljin Mengemudi yang dilakukan pihak kepolisian melalui mobil layanan keliling, dan juga counter-counter yang dapat dengan mudah dijumpai di tempat tempat umum memang memberikan kemudahan kepada masyarakat yang akan memperpanjang Surat ljin Mengemudi. Cara demikian juga efisien, dan efektif, menghemat biaya dan tenaga bagi pemegang Kartu Surat ljin Mengemudi. Namun dalam perspektif hukum (adminsitrasi), sistem ini menimbulkan sedikit permasalahan sehubungan tidak dilakukannya tes ulang kesehatan pemohon. Mengingat perubahan kondisi kesehatan pemohon dapat berubah setiap waktu, apalagi dalam rentang masa berlakunya Surat ljin Mengemudi selama 5 (lima) tahun, tentunya semua kemungkinan terkait kondisi kesehatan seseorang dapat saja terjadi, sehingga dapat mempengaruhi kemampuan seseorang dalam mengendalikan kendaraan bermotor. Sehubungan dengan fungsi Surat ljin Mengemudi merupakan rekomendasi atau pembolehan seseorang untuk mengendarai kendaraan bermotor, sedangkan untuk mengendarai kendaraan bermotor diperlukan kondisi kesehatan yang prima, maka dalam penerbitan perpanjangan Surat ljin Mengemudi, hendaknya dilakukan tes ulang kesehatan pemohon.

\section{METODE PENELITIAN}

1. Teknik pengumpulan data

Metode pengumpulan data merupakan salah satu cara untuk menyelidiki atau menguji dengan teliti dalam mencari fakta kejelasan satu permasalahan beserta pemecahan masalah. Beberapa teknik dalam mengumpulkan data pembuatan skripi ini adalah:

a. Observasi

Metode ini dilakukan dengan cara mengunjungi langsung Kesatuan Lalulintas (Satlantas) Polres Sukabumi Kota Bagian Mobil SIM keliling dan melakukan pengamatan langsung terhadap sistem yang berjalan, sehingga dapat diperoleh data yang tepat dan akurat.

b. Wawancara

Untuk mendapatkan informasi secara lengkap, dilakukan metode tanya jawab dengan narasumber (Petugas) mengenai sistem perpanjangan SIM pada mobil SIM keliling.

c. Studi Pustaka

Dengan mencari informasi dari beberapa sumber-sumber seperti website, buku-buku, jurnal dan sebagainya. Sumber-sumber ini digunakan untuk melengkapi data-data dan informasi yang dibutuhkan dalam penyusunan laporan.

2. Model Pengembangan Sistem

a. Analisa Kebutuhan Software

Langkah ini merupakan tahap pengumpulan data, analisa interface guna menentukan solusi dari perangkat lunak yang diperlukan yang nantinya akan digunakan sebagai proses perancangan web.

b. Desain

Proses desain terbagi kedalam beberapa bagian desain yakni desain database, desain sistem dan desain inerface, pada skripsi ini software yang digunakan untuk mendesain database adalah Entity Relationship Diagram (ERD) , Logical Relational Structure (LRS) ada pula software Unified Modeling Language (UML) yang digunakan sebagai perangkat tool untuk mendukung pengembangan sistem tersebut.

c. Code Generation

Proses pembuatan coding atau pengkodean merupakan peterjemahan desain ke dalam bahasa yang bisa dikenali oleh komputer, bahasa pemograman yang di gunakan adalah 
bahasa pemograman php serta menggunakan javascript untuk memberikan tampilan yang tam pak lebih interaktif.

\section{d. Testing}

Proses menemukan kesalahan terhadap sistem yang telah diimplementasikan kedalam sebuah software pada skripsi ini teknik pengujian yang akan dilakukan dalah teknik blackbox testing.

e. Support

Setelah melakukan analisis desain dan pengkodean maka sistem sudah jadi akan digunakan user maka dari itu support dari pengembang masih perlu dilakukan untuk pemeriksaan secara berkala.

\section{HASIL DAN PEMBAHASAN}

1. Proses Bisnis Sistem

Pemohon yang akan melakukan perpanjangan SIM mendatangi mobil SIM keliling dan mengambil nomor antrian, kemudian mengisi formulir yang sudah disediakan dengan melengkapi data diri (KTP) dan SIM yang lama. Setelah itu menunggu antrian untuk dipanggil dan dilakukan verifikasi data.

Pemohon menyerahkan formulir kepada Petugas dengan melampirkan berkas yang diperlukan, kemudian Pemohon diarahkan untuk melakukakn foto dan melakukan tanda tangan untuk pengambilan SIM yang baru.

a. Tahapan Analisis

Analisis kebutuhan dalam sistem informasi pendataan kelulusan uji simulator yaitu sebagai berikut:

Halaman User:

A1. User dapat melakukan pendaftaran akun

A2. User dapat melakukan login

A3. User dapat melakukan pendaftaran perpanjangan SIM

A4. User dapat mencetak bukti pendaftaran

Halaman Admin:

B1. Admin dapat melakukan login

B2. Admin dapat melihat data perpanjangan SIM

B3. Admin dapat memperoses data perpanjangan SIM

B4. Admin dapat mencetak laporan perpanjangan SIM

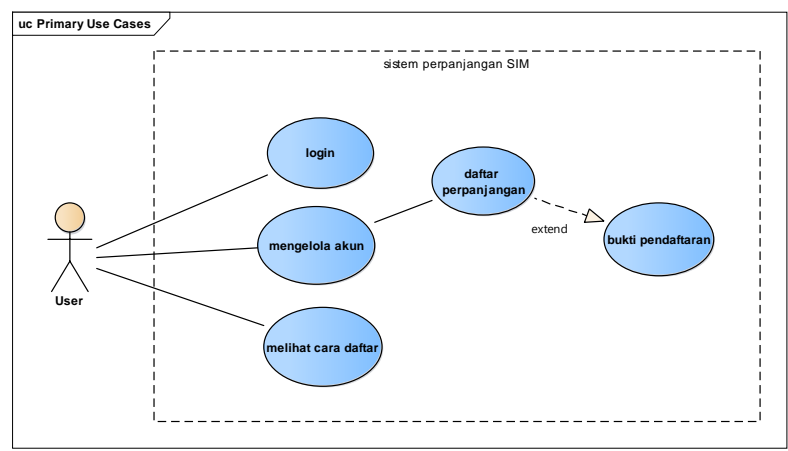

Gambar 1. Use Case Diagram User 
IJSE - Indonesian Journal on Software Engineering, Vol.5, No. 2, Desember 2019, 1-12 pISSN: 2461-0690 I elSSN: 2714-9935

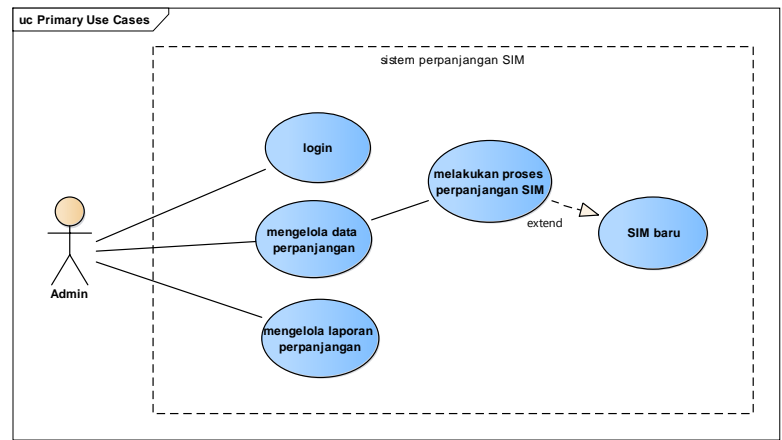

Gambar 2. Use Case Diagram Admin

Tabel 1. Use Case Diagram Pendaftaran Akun

\begin{tabular}{|l|l|}
\hline Use Case Name & Daftar Akun \\
\hline Requirement & A1 \\
\hline Goal & $\begin{array}{l}\text { User dapat melakukan pendaftaran akun di } \\
\text { sistem agar bisa melakukan login untuk } \\
\text { pendaftaran perpanjangan SIM }\end{array}$ \\
\hline Pre-Conditions & User masuk ke sistem \\
\hline Post-Conditions & Sistem menampilkan halaman daftar akun \\
\hline Failed end Condition & User tidak memilih halaman daftar akun \\
\hline Primary Actors & User \\
\hline Main Flow /Basic Path & $\begin{array}{l}\text { 1. Sistem menampilkan halaman awal } \\
\text { 2. User memilih menu daftar akun } \\
\text { 3. User mengisi data diri yang dibutuhkan } \\
\text { untuk bisa login dan daftar perpanjangan } \\
\text { SIM di sistem }\end{array}$ \\
\hline Invariant & User memilih menu batal \\
\hline
\end{tabular}

Tabel 2. Use Case Diagram Login

\begin{tabular}{|l|l|}
\hline Use Case Name & Login \\
\hline Requirment & A2 \\
\hline Goal & $\begin{array}{l}\text { User dapat melakukan login dengan memasukkan } \\
\text { username dan password }\end{array}$ \\
\hline Pre-condition & User login dan masuk ke sistem \\
\hline Post-condition & Sistem menampilkan halaman user \\
\hline Failed end condition & $\begin{array}{l}\text { User tidak melakukan login dengan tidak } \\
\text { memasukkan username dan password }\end{array}$ \\
\hline Primary Actor & User \\
\hline Main Flow/Basic Path & $\begin{array}{l}\text { 1. User login terlebih dahulu jika sudah mempunyai } \\
\text { username dan password dan klik login. }\end{array}$ \\
\hline Invariant & User memilih menu batal \\
\hline
\end{tabular}

Tabel 3. Use Case Diagram Pendaftaran Perpanjangan SIM

\begin{tabular}{|l|l|}
\hline Use Case Name & Daftar \\
\hline Requirement & A3 User dapat melakukan pendaftaran \\
\hline Goal & $\begin{array}{l}\text { User } \\
\text { perpanjangan SIM di sistem }\end{array}$ \\
\hline Pre-Conditions & User login dan masuk ke sistem \\
\hline
\end{tabular}




\begin{tabular}{|l|l|}
\hline Post-Conditions & Sistem menampilkan halaman daftar \\
\hline Failed end Condition & $\begin{array}{l}\text { User tidak melakukan login dan tidak } \\
\text { memasukan username dan password }\end{array}$ \\
\hline Primary Actors & User \\
\hline Main Flow /Basic Path & 1. Sistem menampilkan halaman daftar \\
& 2. User melengkapi data untuk pendaftaran \\
& perpanjangan SIM \\
& 3. User dapat mencetak bukti pendaftaran \\
\hline Invariant & User memilih menu batal \\
\hline
\end{tabular}

Tabel 4. Use Case Diagram Cetak Bukti Pendaftaran

\begin{tabular}{|l|l|}
\hline Use Case Name & Bukti Pendaftaran \\
\hline Requirement & A4 \\
\hline Goal & $\begin{array}{l}\text { User dapat mencetak bukti pendaftaran } \\
\text { setelah melengkapi data di halaman daftar } \\
\text { perpanjangan SIM }\end{array}$ \\
\hline Pre-Conditions & $\begin{array}{l}\text { User telah melakukan pendaftaran } \\
\text { perpanjangan SIM di sistem }\end{array}$ \\
\hline Post-Conditions & $\begin{array}{l}\text { Sistem menampilkan halaman cetak bukti } \\
\text { pendaftaran }\end{array}$ \\
\hline Failed end Condition & $\begin{array}{l}\text { User tidak melengkapi data diri di halaman } \\
\text { daftar perpanjangan SIM }\end{array}$ \\
\hline Primary Actors & User \\
\hline Main Flow /Basic Path & $\begin{array}{l}\text { 1. Sistem menampilkan cetak bukti } \\
\text { pendaftaran setelah user melengkapi data } \\
\text { diri di halaman pendaftaran perpanjangan } \\
\text { SIM }\end{array}$ \\
\hline Invariant & User memilih menu batal cetak \\
\hline
\end{tabular}

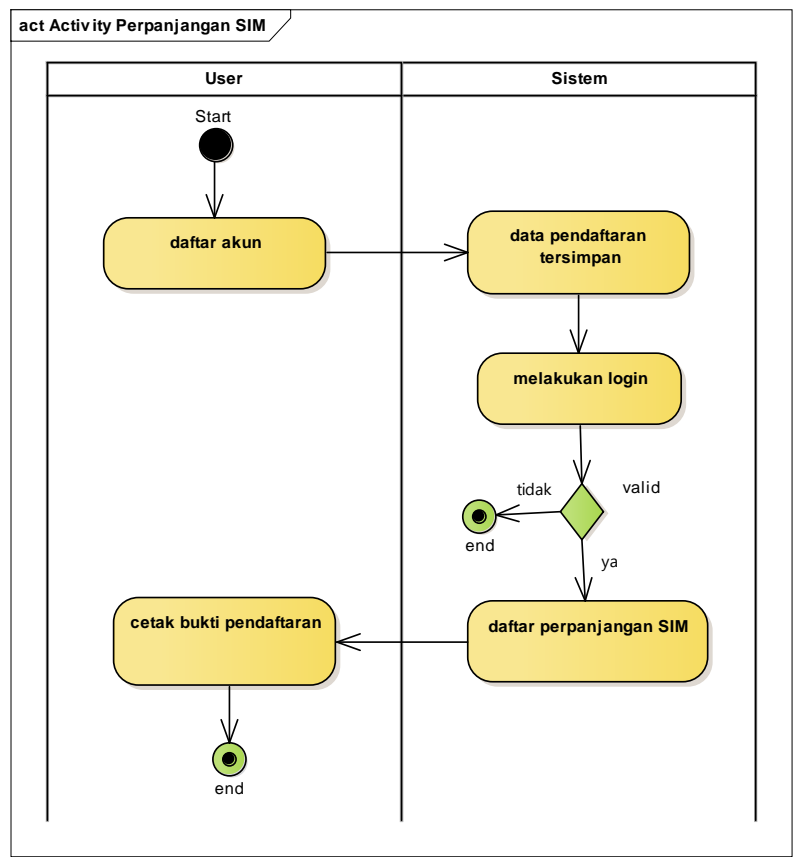

Gambar 3. Activity Diagram Pendaftaran Perpanjangan SIM 
IJSE - Indonesian Journal on Software Engineering, Vol.5, No. 2, Desember 2019, 1-12 pISSN: 2461-0690 I elSSN: 2714-9935

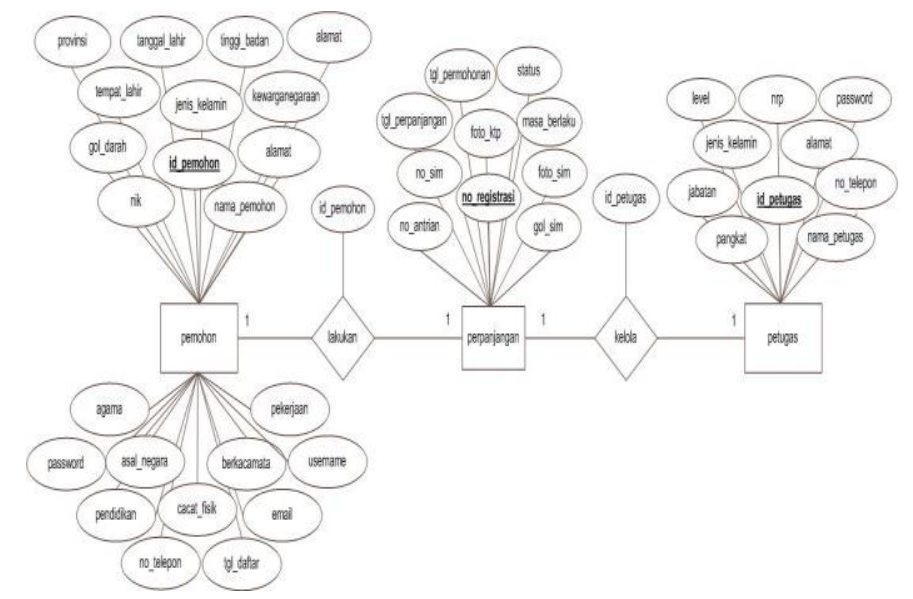

Gambar 4. Entity Relational Diagram Perpanjangan SIM

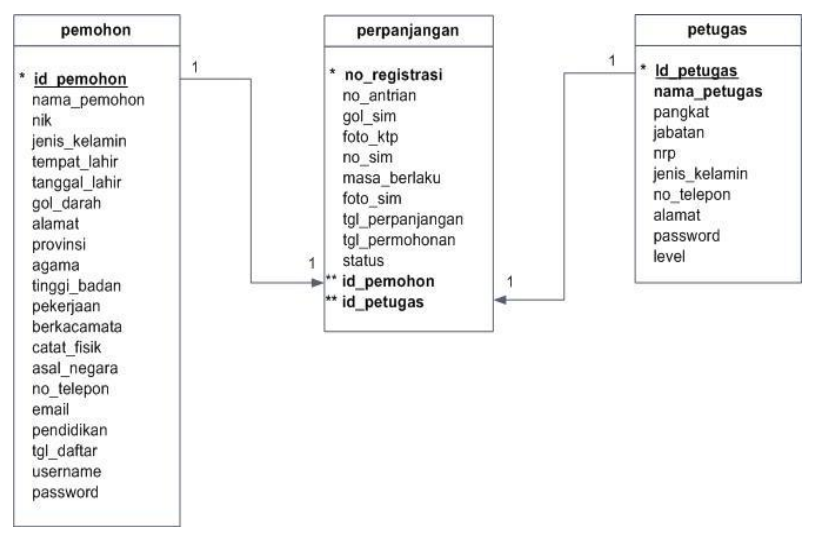

Gambar 5. Logical Relational Structure Perpanjangan SIM

b. Spesifikasi File

Menjelaskan tentang file atau label yang terbentuk dari transformasi ERD (dan atau file-file penunjang untuk web). File-file ini tersimpan pada database dengan parameter-parameter sebagai berikut:

1. Spesifikasi File Petugas
Nama File : Petugas
Akronim : petugas
Fungsi : Untuk menyimpan data petugas
Tipe File : File Master
Organisasi File : Indexed Sequensial
Akses File : Random
Media : Hardisk
Panjang Record: 500 karakter
Kunci Field : id_petugas
Software : MySQL

2. Spesifikasi File Perpanjangan

Nama File : Perpanjangan

Akronim : perpanjangan

Fungsi : Untuk menyimpan data perpanjangan SIM

Tipe File : File Transaksi

Organisasi File : Indexed Sequensial

Akses File : Random

Media : Hardisk 
Panjang Record : 391 karakter

Kunci Field : no_registrasi

Software : MySQL

3. Spesifikasi File Pemohon

$\begin{array}{ll}\text { Nama File } & \text { : Pemohon } \\ \text { Akronim } & \text { : pemohon } \\ \text { Fungsi } & \text { : Untuk menyimpan data pemohon } \\ \text { Tipe File } & \text { : File Master } \\ \text { Organisasi } & \text { File Indexed Sequensial } \\ \text { Akses File } & : \text { Random } \\ \text { Media } & \text { : Hardisk } \\ \text { Panjang Record: } 700 \text { karakter } \\ \text { Kunci Field : : id_pemohon } \\ \text { Software : MySQ }\end{array}$

c. User Interface

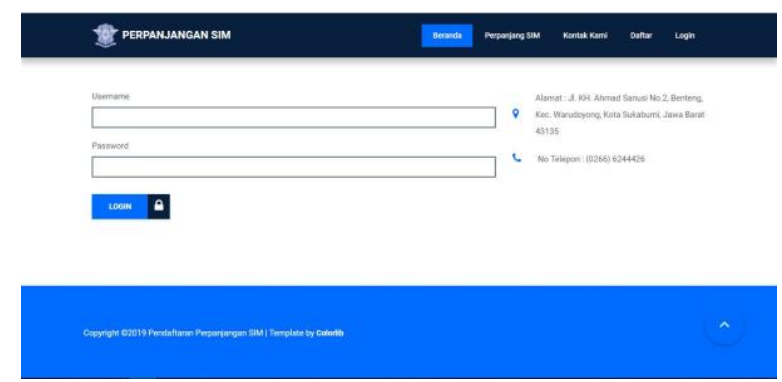

Gambar 6. User Interface Halaman Login Admin
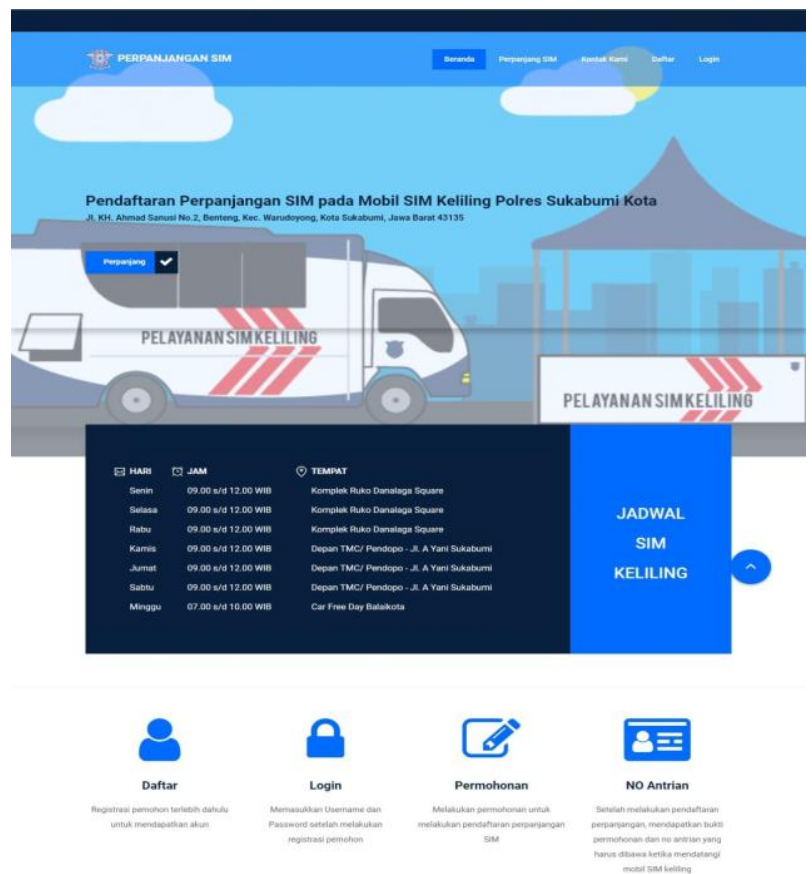

Gambar 7. User Interface Halaman Beranda 
IJSE - Indonesian Journal on Software Engineering, Vol.5, No. 2, Desember 2019, 1-12 pISSN: 2461-0690 I elSSN: 2714-9935

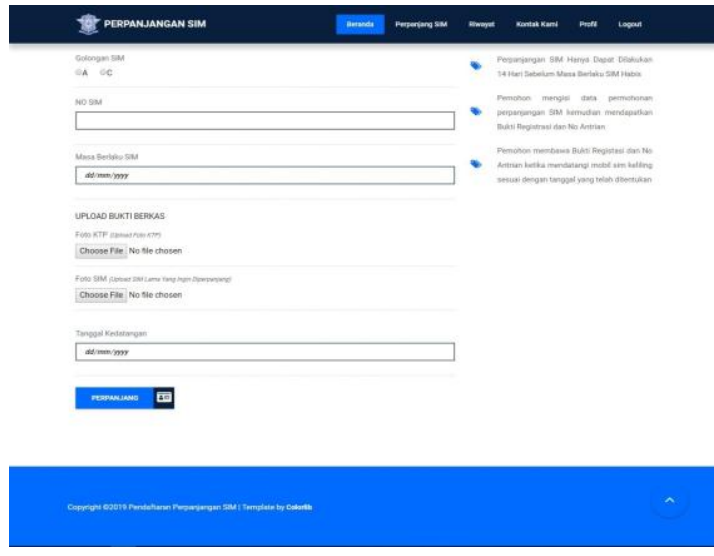

Gambar 8. User Interface Halaman Daftar Perpanjangan
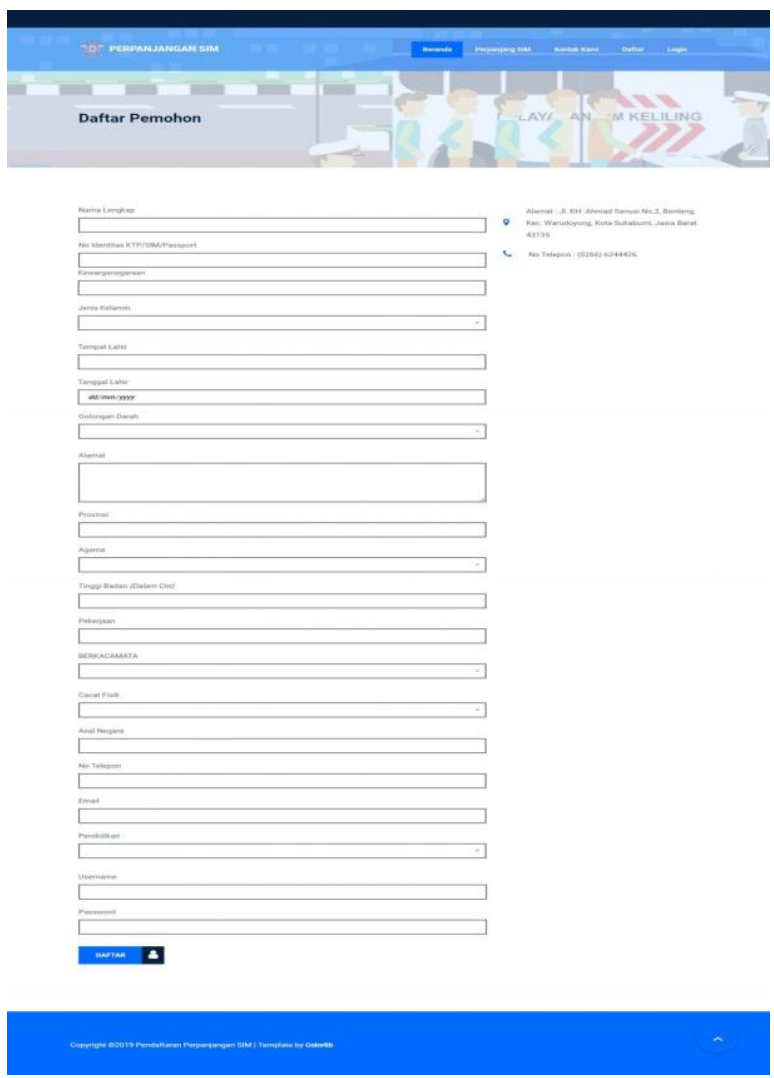

Gambar 9. User Interface Halaman Daftar Pemohon (Akun)

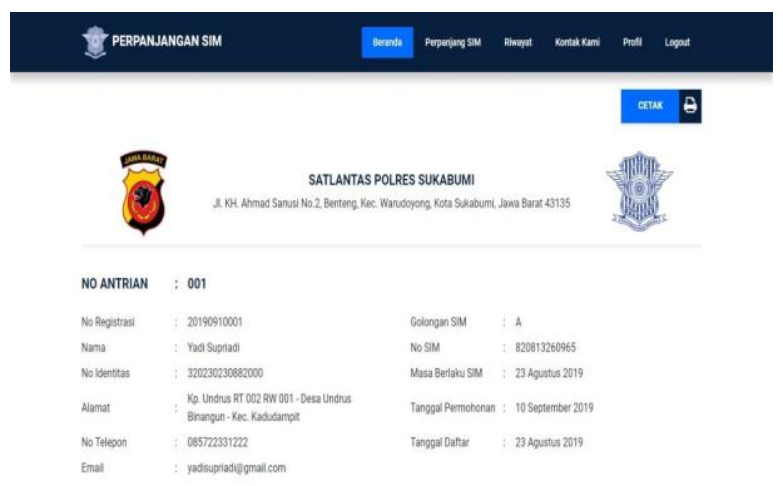

Gambar 10. User Interface Bukti Daftar Perpanjangan 
d. Software Architecture

1) Deployment diagram

Menggambarkan tata letak sebuah sistem secara fisik, menampakkan bagian-bagian software yang berjalan pada bagian-bagian hardware.

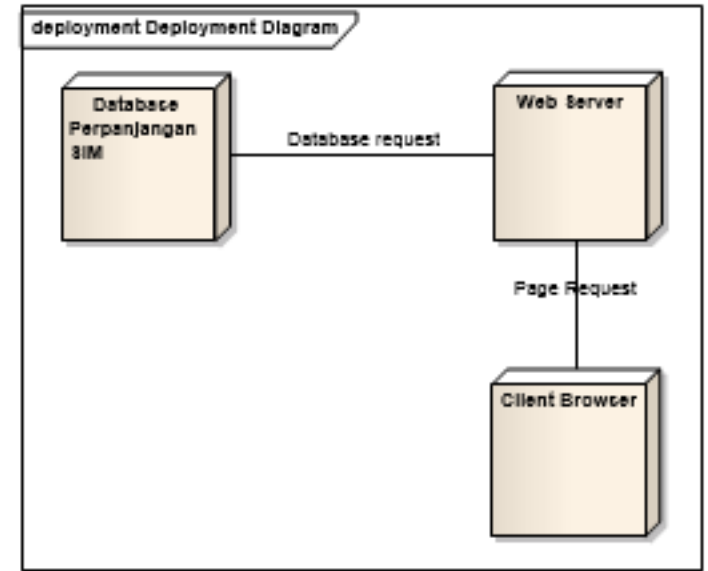

Gambar 11. Deployment diagram

2) Component diagram

Component diagram menggambarkan struktur dan hubungan antar komponen piranti lunak termasuk ketergantungan (dependency).

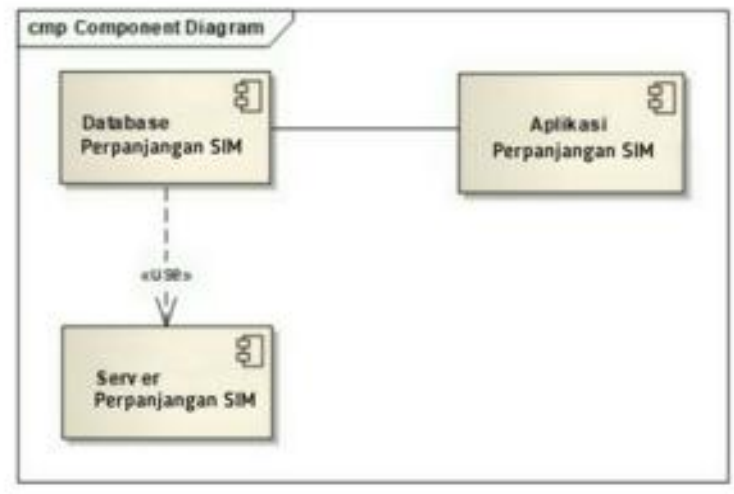

Gambar 12. Component diagram

\section{E. KESIMPULAN}

Berdasarkan pembahasan yang telah dilakukan pada bab-bab sebelumnya, maka dapat diambil beberapa kesimpulan dari penelitian ini sebagai berikut :

1. Sistem pendaftaran perpanjangan SIM berbasis web pada Mobil SIM keliling Polres Sukabumi kita diharapkan dapat mempermudah Pemohon SIM dalam melakukan perpanjangan SIM tanpa harus antri lama di mobil SIM keliling, melainkan bisa diakses dimana saja.

2. Pemohon SIM dapt dengan mudah mencetak bukti pendaftaran yang didalamnya sudah terdapat nomor antrian untuk pengambilan SIM baru. 
Berdasarkan hasil analisis dan pengembangan yang telah dilakukan, maka dapat diberikan beberapa saran sebagai berikut:

1. Perlu adanya pelatihan petugas dalam pengoperasian sistem untuk meningkatkan kualitas sumber daya manusia.

2. Melakukan pengamanan data agar terhindar dari hal-hal yang tidak diinginkan.

3. Mengadakan pemeliharaan dan pengoperasian sistem, sehingga terjadinya kesalahan yang berhubungan dengan sistem yang sedang berjalan dapat segera diketahui.

\section{REFERENSI}

Abidin, R. (2016). Beberapa Hal Yang Harus Diketahui Tentang PHP 7.

Anggraini, P. dan D. P. M. (2019). Sistem Informasi Administrasi Pembuatan Surat Izin Mengemudi pada Kantor Kepolisian Republik Indonesia Sektor Pasaman dengan Menggunakan Bahasa Pemrograman Java. Jurnal Teknologi.

Asropudin, P. (2013). Kamus Teknologi Informasi. Bandung. CV Titian IImu.

Bootstrap. (2018). No Title.

Henry, S. (2014). Manajemen Sumber Daya Manusia. Yogyakarta. Bagian Penerbitan Sekolah Tinggi Ilmu Ekonomi YKPN.

Https://www.polri.go.id. (1992). Surat ljin Mengemudi (SIM). Retrieved from https://www.polri.go.id/layanan-sim.php ((diakses pada 18 Agustus 2019 : 16.30 WIB)

Kardianawati, S. dan A. (2014). Rancang Bangun Sistem Perpanjangan Masa Berlaku SIM Online (Studi Kasus: Kepolisian Negara Republik Indonesia Daerah Jawa Tengah Resor Pati Satuan Lalulintas) (Vol. 1).

Pahlevi, O., Mulyani, A., \& Khoir, M. (2018). Sistem Informasi Inventori Barang Menggunakan Metode Object Oriented Di Pt. Livaza Teknologi Indonesia Jakarta. PROSISKO: Jurnal Pengembangan Riset Dan Observasi Sistem Komputer, 5(1), 27-35.

Putra, R. L. (2016a). Studi tentang pelayanan SIM Keliling di Satuan Lalulintas Kota Samarinda. E-Jurnal Pemerintahan Integratif, 4(1).

Putra, R. L. (2016b). Studi tentang pelayanan SIM Keliling di Satuan Lalulintas Kota Samarinda. E-Jurnal Pemerintahan Integratif, 4(1), 127.

Rouse, M. (2018). MySQL.

Rustopo, I. N. dan I. P. (2016). Implementasi Surat Izin Mengemudi di Satuan Penyelenggaraan Administrasi SIM Colombo Surabaya. Jurnal IImu Administrasi Negara, 1(1).

Suhartono, S. (2015). Perpanjangan Surat Izin Mengemudi Melalui Mobil Layanan dan SIM Corner. Jurnal IImu Hukum, 11(21), 13.

Suryani, Des, A. Y. dan M. Z. (2018). Aplikasi Legalitas IM Berbasis Mobile (Studi Kasus: Polisi Resort Rengat). IT Journal Research and Development, 2(2).

Suryawan, D. K. (2015). Kulaitas Pelayanan Perpanjangan SIM Golongan C. Majalah IImiah Dian IImu, 60.

Sutabri, T. (2012). Analisis Sistem Informasi. Yogyakarta: Andi Offset. 